\title{
O EFEITO DO TREINO DA VISÃO PERIFÉRICA NA ZONA DOS GOLS DO FUTSAL -TREINO DA VISÃO PERIFÉRICA
}

\author{
The effect of the peripheral vision training of futsal goal zone
}

Nelson Kautzner Marques Junior, Vernon Furtado da Silva

\section{Resumo}

A percepção visual é importante para o atleta do futsal realizar suas ações, na partida, com qualidade. A visão periférica otimiza o ataque, pois o esportista tem mais chances de gol. $\mathrm{O}$ objetivo desse estudo foi determinar o efeito do treino da visão periférica na zona dos gols do futsal. Dez jovens jogadores de futsal, com 10,4 $\pm 2,31$ anos, treinaram por 25 dias. $O$ grupo experimental (GE) fez 25 sessões do treino da visão periférica e o grupo controle (GC) realizou 15 sessões do treino tradicional do futsal, efetuando 10 sessões do treino da visão periférica. $A$ pesquisa teve três turnos de um campeonato em dupla, que foram filmados e, depois, analisados por scout. A Anova three way (grupo $x$ turno $x$ zona de gols) foi significativa apenas entre as zonas $F(4,54)=19,44, p=$ 0,00 . Nas comparações entre as médias Tukey HSD detectou diferença significativa $(p \leq 0,05)$ da média de gols da zona dois, em comparação às demais zonas (três, cinco, seis e oito). O teste "t" independente identificou diferença significativa $(p \leq 0,05)$, em todo o campeonato, da zona dois em relação às demais zonas. O GE e o GC tiveram resultados parecidos, nas zonas de gols, mais tentos na zona dois. Não se pode concluir, com precisão, os achados parecidos das zonas de gol do GE e do GC.

Palavras-chave: Visão, Visão Periférica, Treino, Futsal.

\begin{abstract}
Visual perception is important for the futsal player to practice the actions of the match with good skill. The peripheral vision is important for the attack, because the sportsman has more chances of goals. The objective of the study was to determine the effect of the peripheral vision training of futsal goal zone. Ten young futsal players, with an average of $10.4 \pm 2.31$ years, trained futsal for 25 days. Experimental group (EG) practiced 25 sessions of the peripheral vision training, control group (CG) practiced 15 sessions of futsal traditional training and 10 sessions of the peripheral vision training. The research included three championships in pairs, each one recorded, and after analyzed by scout, observing the matches on television. Three way Anova (group $x$ match $x$ goal zone) was significant for zones $F(4.54)=19.44, p=0.00$. Tukey HSD determined significant $(p \leq 0.05)$ difference of the two goals zones than the other zones (three, five, six and eight). Independent $T$ Test was significant $(p \leq 0.05)$ for two goal zones than other zones in the whole championship. EG and CG had similar results of the goal zones, more goals of the two goal zones. In conclusion, the study does not account for the explanation about similar goals zone of the $E G$ and of the CG.
\end{abstract}

Key words: Vision, Peripheral Vision, Training, Futsal.

\section{INTRODUÇÃO}

A tática no jogo de futsal tem grande importância, pois permite, à equipe, uma adequada movimentação para realizar as tarefas de ataque e de defesa. Cada atleta, para praticar essas ações táticas com excelência, precisa de uma boa percepção visual ${ }^{1}$ e de uma excelente inteligência de jogo ${ }^{2}$. Através da visão, o esportista percebe as primeiras informações sobre o momento do jogo ${ }^{3}$, encaminhando esses dados para o encéfalo, onde ocorre o comando para o atleta resolver a situação-problema da jogada ${ }^{4}$. Então, uma percepção visual de qualidade

Universidade Castelo Branco (Laboratório de Neuromotricidade Humana) - Rio de Janeiro - RJ - Brasil.

Recebido em 22.04.2008. Aceito em 07.08.2008.

Revista de Educação Física 2008 Dez; 143:18-27. Rio de Janeiro (RJ) - Brasil. 
permite uma resposta neuromotora eficaz, durante a jogada ${ }^{5}$. Contudo, o tipo de visão que deve predominar, durante a partida, merece ser a visão periférica, já que esta visão espacial proporciona uma observação ampla do contexto da partida, em 180 graus $^{6}$.

Recentemente, algumas evidências científicas afirmaram que a visão periférica otimiza o ataque, acarretando mais chance de gol ${ }^{7,8}$. Para Navarro e Almeida $^{9}$, o uso da visão periférica, no jogo de futsal, não deve ser somente praticado pelo atleta da linha, pois o goleiro deve fazer o máximo de uso dessa visão espacial. Com o intuito de educar o atleta a atuar na partida de cabeça erguida e, conseqüentemente, proporcionar ênfase na visão periférica, Marques Junior ${ }^{10}$ indicou o treino da visão periférica. Portanto, a visão periférica causa um diferencial dos melhores jogadores para os inferiores ${ }^{11}$. Logo, uma equipe que aprender o treino da visão periférica talvez consiga fazer gols em zonas da quadra mais próximas da meta. Será que o treino da visão periférica permite ao time de futsal realizar mais gols próximos da meta? As referências do futsal não podem responder a esta questão ${ }^{12,13}$, tornando importante uma pesquisa para este esporte. O objetivo desse estudo foi, portanto, determinar o efeito do treino da visão periférica na zona dos gols do futsal.

\section{METODOLOGIA}

\section{Sujeitos}

Os sujeitos do estudo eram meninos, da comunidade de Ititioca e Atalaia, Niterói, Rio de Janeiro. Participavam do Projeto de Esportes do Orfanato Lar da Criança Padre Franz Neumair, em Ititioca. O grupo da investigação foi composto de 10 atletas de futsal, não federados, oito na linha e dois no gol. Os 10 meninos tinham 10,4 $\pm 2,31$ anos, estatura de $139,2 \pm 10,30 \mathrm{~cm}$ e massa corporal total de $40,7 \pm 12,29 \mathrm{~kg}$. As medidas da estatura e da massa corporal total foram estabelecidas conforme as normas de Matsudo $^{14}$. A balança e o estadiômetro, utilizados na pesquisa, foram da marca Filizola, de fabricação nacional. A amostra foi observada jogando futsal, quando ocorreu uma divisão intencional da equipe em grupo experimental (GE, $n=5$ ) e grupo controle ( $G C, n=5)$, conforme a qualidade técnica e tática de cada atleta. Esta investigação respeitou todas as normas do Conselho Nacional em Saúde (1997) envolvendo seres humanos. Todos os participantes da pesquisa foram informados sobre a natureza do estudo, tendo os responsáveis pelos jovens atletas assinado um Termo de Consentimento. O presente trabalho foi aprovado pelo Comitê de Ética em Pesquisa da UCB, de acordo com a Resolução 196/96 - protocolo número 0028/2007.

\section{Teste de CLEM}

A hemisfericidade dos jovens do futsal foi estabelecida pelo teste de CLEM, de acordo com as informações de Oliveira, Beltrão e Da Silva ${ }^{15}$.

\section{Treino dos sujeitos e resultados no campeonato em dupla}

Os atletas de futsal, não-federados, se encontravam na etapa de especialização inicial, treinando duas vezes por semana, no período de 9 às 10 horas da manhã. Os jovens praticaram 25 sessões, tendo, como modelo de periodização, a periodização tática que exige, em todas as atividades, a presença da bola ${ }^{16}$. $O$ intuito dessas sessões foi ensinar o treino da visão periférica para o GE. O GC realizou 15 sessões do futsal, sem a procupação em ensinar o atleta a jogar de cabeça erguida, além de 10 sessões do treino da visão periférica. A FIGURA 1 expõe a diferença do campo visual, conforme o tipo de sessão.

FIGURA 1

DIFERENÇA DO CAMPO VISUAL, CONFORME O TIPO DE SESSÃO.
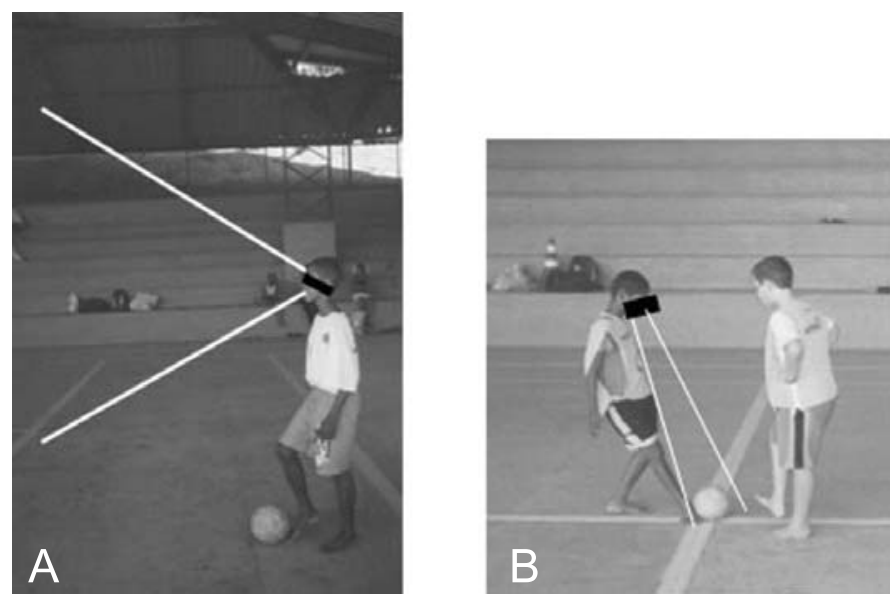

(a) Atleta que faz o treino da visão periférica com visão de $180^{\circ} \mathrm{e}$ (b) jogador da sessão comum do futsal com visão de $20^{\circ}$.

No macrociclo um, foram prescritas nove práticas em bloco, compostas pelo treino técnico e, depois, o jogo. Cada tipo de sessão durou 30 minutos, mas, no treino técnico, o 
GE se exercitou com um professor e o GC, trabalhou com outro educador físico. Cada amostra ocupou meia quadra para realizar essas atividades. O GE e o GC praticaram os mesmos exercícios técnicos, com as seguintes tarefas: condução da bola, passe, chute, drible, cabeçada, domínio, cruzamento para área, cobrança de pênalti, corner, tiro de canto e cobrança de falta direta. Esses fundamentos eram praticados, isoladamente, e, também, com a união de alguns deles, como, por exemplo, a condução da bola até um metro e, depois, a realização do chute para o gol. A única diferença do trabalho do GE para o GC foi ensinar a jogar de cabeça erguida.

Terminado o treino técnico, ocorria um jogo do GE versus o GC. Como forma de incentivar o GE a atuar na partida com prioridade nas jogadas de cabeça erguida, caso o atleta a abaixasse por muito tempo, perdia a bola, passando-a para o GC. Como jogar de cabeça erguida ocasionasse um decréscimo neuromotor do GE, como forma de equilibrar o jogo, já que durante os nove jogos treinos o GC venceu todos, foi determinado que o GC só podia dar dois toques na bola.

Finalizada as nove sessões do macrociclo um, aconteceu o primeiro turno do campeonato em dupla de futsal, onde os resultados foram os seguintes: GE $A$ três $x$ seis GC A (classificatória), GE $B$ quatro $x$ zero $G C B$ (classificatória), GE A cinco $x$ quatro GC B (3 lugar) e GE $B$ seis $x$ sete $G C A$ ( 1 ํ lugar). $O$ goleiro do $G E$ foi o primeiro e o GC ficou em segundo.

No macrociclo dois, foram prescritas seis sessões, duas práticas em bloco, para averiguar o aprendizado do macrociclo um pelos jovens, através do treino cognitivo. No treino cognitivo, o GE tinha que estruturar uma sessão para a sua amostra com o que foi ensinado no macrociclo um, tendo o GC realizado o mesmo. Os professores prescreveram o treino cognitivo para se certificarem de que os meninos poderiam receber um conteúdo mais complexo.

Após esse momento, ocorreram quatro dias de prática aleatória, sendo esta uma forma de se elaborar o ensino do aprendizado motor ${ }^{17}$. A ênfase do trabalho foi dada ao treino situacional e ao jogo, durando os dois tipos de treino, cada um, 30 minutos. Durante o treino situacional, o GE teve um professor e o GC, outro. A tarefa prescrita, no treino situacional, foi composta de mini-jogos, acontecendo em meia quadra, sendo dois contra dois, com um goleiro. Nesse treino, ocorreram três ataques de uma dupla e outra, defendendo. Em seguida, a dupla que foi defesa, passou a atacar. Esta troca, entre ataque e defesa, ocorreu durante toda a sessão, que teve duração de trinta minutos. A diferença do treino situacional do GE para o GC era ensinar a jogar de cabeça erguida. No treino situacional do GE, caso o atleta abaixasse a cabeça por muito tempo, era marcado um pênalti.

Para caracterizar a prática aleatória, a sessão do GE e do GC, de vez em quando, era interrompida, sem uma ordem pré-estabelecida, quando os meninos, dos dois grupos, realizavam atividades de outros esportes. Assim, os jovens praticaram a cortada do voleibol e, após algumas ações, o professor ensinava cabeçada com balanceio dos braços, a fim de proporcionar maior elevação do centro de gravidade, baseado nas investigações de salto vertical ${ }^{18,19}$. O mesmo foi ensinado para a saída do gol com bola aérea.

Ainda, na prática aleatória, após o exercício, os jogadores retornavam para o treino situacional ou passavam ao treino de outro esporte, sendo o atleta orientado a fazer transferência para o futsal. Baker, Horton, Robertson-Wilson e Wall ${ }^{20}$ afirmam que essa iniciativa proporciona um aumento do vocabulário neuromotor e evita a especialização precoce. A prática aleatória também esteve baseada em algumas escolas tradicionais do treinamento esportivo, como as da Austrália, da ex-Alemanha Oriental, de Cuba e da ex-União Soviética, que indicam, quando da iniciação esportiva, a realização de mais de uma modalidade ${ }^{21}$. Também, a prática aleatória, com diversas tarefas "surpresas", quando o jogador não sabe qual exercício irá acontecer, são excelentes para ocasionar rápida retenção do conteúdo passado ${ }^{22}$.

$\mathrm{Na}$ prática aleatória, foram realizadas, ainda, as seguintes modalidades esportivas: salto em distância, com o intuito de tentar que o esportista chegasse antes na bola; $10 \mathrm{~m}$ rasos, para que os jogadores aprendessem outra técnica de corrida que proporcionasse, em certos momentos do futsal, mais rapidez de deslocamento; e o salto triplo, para que o futebolista aprendesse a saltar com uma das pernas por cima do goleiro, já que ele se encontra no solo, na saída do gol, em um lance de ataque da partida.

Após o treino situacional, era realizado o jogo do GE versus o GC. Mas, no macrociclo dois, as partidas passaram a ser realizadas conforme a regra oficial, pois o GE já estava familiarizado e com facilidade em jogar de cabeça erguida. Finalizada as seis sessões do macrociclo dois, aconteceu o segundo turno do campeonato em dupla de futsal, onde a tabela e os resultados foram os seguintes: 
FIGURA 2 ZONAS DOS GOLS DO FUTSAL.

\begin{tabular}{|c|c|c|c|c|}
\hline Defesa & Meio-campo Defensivo & & Ofensivo & Ataque \\
\hline & & 7 & 4 & 1 \\
\hline & & 8 & 5 & 2 \\
\hline & & 9 & 6 & 3 \\
\hline
\end{tabular}

GE A oito x um GC B (classificatória), GE B sete $x$ quatro GC B (classificatória), GC A cinco $x$ quatro GC B (3ำ lugar) e GE $A$ seis $x$ sete GE $B$ (1ㅇlugar). $O$ goleiro do GE foi o primeiro e o GC ficou em segundo.

Após o segundo turno, foi constatado que o GE fez a maioria dos gols próximo da meta, na zona 2 (FIGURA 2), sendo melhor nesse turno, fazendo a final. Ressalta-se que esse turno do campeonato ocorreu após 15 sessões do treino da visão periférica, visando educar o atleta de futsal a jogar de cabeça erguida.

Com o intuito de observar se o treino da visão periférica permite mais gols próximos da meta e, conseqüentemente, ocasiona melhores desempenhos para a dupla do futsal, foi aplicado, no macrociclo três, a mesma sessão para o GE e para o GC.

No macrociclo três, foram prescritas 10 sessões, seis práticas em bloco, ao se iniciar esse ciclo, e quatro práticas aleatórias, compostas pelas mesmas modalidades do macrociclo dois (atletismo e voleibol). No macrociclo três, aconteceu o treino tático e, depois, o jogo, com duração de 30 minutos, cada tipo de atividade. O GE e o GC realizaram o treino tático juntos, utilizando toda a quadra. As duas amostras praticaram, na sessão tática, o treino da visão periférica que educa a jogar de cabeça erguida. No treino tático, os atletas aprenderam a "rodar", isto é, os jogadores trocavam de posição (ala para o pivô, pivô para fixo, etc), visando progredir da defesa para o ataque. Essa sessão foi conduzida com jogadores do GE e do GC, se exercitando na mesma equipe, orientados por dois professores. O treino tático foi prescrito com as seguintes variações: feito sem bola, sem marcação, com marcação em meia quadra e com marcação em toda a quadra. Terminada essa tarefa, foi realizado jogo, possuindo, cada equipe, atletas do GE e do GC, sendo os desportistas obrigados a efetuar as atividades "rodando" e, na maior parte da partida, com predomínio da visão periférica, ou seja, jogando de cabeça erguida. Caso estes dois procedimentos não fossem realizados, a equipe perdia a posse da bola. Finalizada as 10 sessões do macrociclo três, aconteceu o terceiro turno do campeonato em dupla de futsal, onde a tabela e os resultados foram os seguintes: GE $A$ três $x$ seis GE $B$ (classificatória), GC A seis $x$ oito GC $B$ (classificatória), GE A três $x$ seis GC A (3ำ lugar) e GE $B$ nove $x 10 \mathrm{GC} B$ ( 1 - lugar). $O$ goleiro do $\mathrm{GC}$ foi o primeiro e o do GE foi o segundo. As colocações finais do futsal adaptado foram as seguintes: $1^{\circ}$ lugar $\mathrm{GE} B$, com 11 pontos; $2^{\circ}$ I lugar GC A, com 9 pontos; 3 ㅇ lugar GC B, com 8 pontos; e 4 Iugar GE A, com 6,5 pontos. Os atletas da linha do GE fizeram um total de 17,5 pontos e o GC alcançou 17 pontos. No gol, o GE venceu, com 13 pontos, e o GC ficou em $2^{\circ}$ lugar, com 11 pontos. Somando a pontuação da linha e do gol, o GE conseguiu 30,5 pontos e o GC obteve 28 pontos.

\section{Regulamento do campeonato em dupla, coleta de dados e análise dos jogos}

No campeonato em dupla, foram praticadas as diferentes tarefas de ataque (a até c), por três tentativas, e todo início das tarefas (a até d) começaram com saída do meio-campo:

a) Quando o juiz apitar - O atleta deve praticar uma seqüência ofensiva para frente, até realizar a finalização. Todos precisam tocar a bola, caso contrário a tentativa é anulada, não podendo ser repetida.

b) Quando o juiz apitar - O atleta deve realizar uma seqüência ofensiva, com a marcação de dois atletas

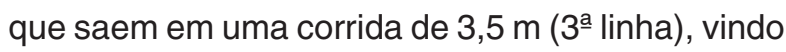
por trás do atacante e tentando interceptar o ataque. Todos precisam tocar a bola, caso contrário, a tentativa é anulada, não podendo ser repetida.

c) Quando o juiz apitar - O atleta deve realizar uma seqüência ofensiva, mas tendo dois defensores posicionados ao lado dos atacantes. Esses zagueiros, inicialmente, se localizam a uma distância de 4,40 m (linha amarela). Dado o início da tarefa, eles podem chegar perto dos atacantes para interceptar a tática ofensiva. Todos precisam tocar a bola, caso contrário, a tentativa é anulada, não podendo ser repetida.

d) Quando o juiz apitar - O atleta deve realizar uma seqüência ofensiva, mas tendo dois defensores de 
frente para os atacantes. Esses zagueiros, inicialmente, se localizam a uma distância de 6,46 m (linha branca). Dado o início da tarefa, eles podem chegar perto dos atacantes para interceptar a tática ofensiva. Todos precisam tocar a bola, caso contrário, a tentativa é anulada, não podendo ser repetida.

e) Ocorre um revezamento no ataque das tarefas da letra a até $\mathrm{c}$, após três tentativas de uma dupla. $\mathrm{O}$ mesmo acontece com os goleiros. Quando o GE ataca, o goleiro é do GC, acontecendo ataque do $\mathrm{GC}$, o goleiro é do GE. Mas, quando joga o GE contra o GE, ou GC contra GC, o goleiro do controle agarra para uma das amostras e o mesmo é praticado pelo goleiro do experimental.

f) Cada colocação, na disputa em dupla, possui a seguinte pontuação para a linha: 1 I lugar (I) 5 pontos (pt); 2ㅇ lugar, 3 pt; $3^{\circ}$ lugar, 2 pt; e 4ㅇlugar, 1,5 pt. Na competição entre goleiros, a pontuação é a mesma que dos jogadores, sendo: $1^{\circ}$ lugar, 5 pt; e $2^{\circ}$ lugar, 3 pt.

g) Em caso de empate, acontece pênalti. Também, se ocorrer alguma infração, o atleta recebe um cartão que resulta em pênalti (amarelo - 1 pênalti, vermelho -2 cobranças).

O campeonato em dupla foi jogado em meia quadra, com 12 m de comprimento por 13,98 m de largura, com o intuito dos jogos serem filmados na lateral da meia quadra, com a câmera Sony Handycam Vision CCD-TRV 12 e fita Sony Digital $8 \mathrm{~mm}$, estando o pesquisador em cima de uma cadeira para coletar todos os dados com a filmadora. A filmagem aconteceu a uma distância de um metro do campo de jogo. Os recursos tecnológicos (filmadora e televisão), utilizados na pesquisa, foram baseados em Jackson e Baker ${ }^{23}$ e o scout, adotado para determinar as zonas de gols, foi adaptado de Oslin, Mitchell e Griffin ${ }^{24}$. Após a coleta de dados das partidas dos três turnos, em um total de 12 jogos do campeonato em dupla de futsal, as partidas foram analisadas, observando a imagem em televisão CCE 30 polegadas, a uma distância de $87 \mathrm{~cm}$, fazendo registros no scout sobre as zonas que aconteciam os gols. Durante a análise dos jogos, foi utilizado o controle remoto da filmadora, quando necessário, com seus respectivos recursos especiais (voltar, avançar, parar e pausa). Isto aconteceu pois o envio da imagem dos jogos foi da filmadora, via fio ouro, para a televisão.

\section{RESULTADOS}

\section{Análise dos dados}

Os resultados foram apresentados pela média, desvio padrão e percentual. A diferença das zonas de gols, do GE e do GC, foi calculada usando a análise de variância a três fatores (Anova three way), com a configuração $2 \times 3 \times 5$ (grupo x turno x zona de gol), com resultados aceitos com nível de significância de $p \leq 0,05$. $O$ teste posterior de Tukey HSD foi utilizado para determinar diferença das médias, aceitando um nível de significância de $p \leq 0,05$. $O$ teste " $t$ " independente foi aplicado na diferença da zona de gols de todo o campeonato, entre GE e GC, com resultados aceitos com nível de significância de $p \leq 0,05$. Todos os dados estatísticos foram calculados conforme os procedimentos do SPSS 12.0 para o Windows.

A análise do teste de CLEM permitiu determinar a hemisfericidade da amostra. O GE tinha quatro jogadores com hemisfério esquerdo de processamento mental (80\%) e um atleta com hemisfério direito de processamento mental (20\%). O GC tinha similar hemisfericidade ao do $\mathrm{GE}$, três jogadores com hemisfério esquerdo de processamento mental (60\%) e dois futebolistas com hemisfério direito de processamento mental (40\%).

A TABELA 1 expõe a estatística descritiva da zona dos gols (oito, cinco e dois no centro da quadra, seis e três no lado direito do campo) do GE e do GC.

A Anova three way não revelou diferença significativa para grupo $F(1,54)=0,23, p=0,88$, para turno $F(2,54)=1,10, p=0,33$ e nas interações entre grupo $e$ turno $F(2,54)=2,08, p=0,13$, grupo e zona $F(3,54)=0,95$, $p=0,42$, turno e zona $F(3,54)=2,61, p=0,61$, e grupo, turno e zona $F(2,54)=1,46, p=0,23$. No entanto, foi encontrada diferença significativa nas comparações entre as zonas $F(4,54)=19,44, p=0,00$. As comparações específicas entre as zonas foram realizadas por Tukey HSD, que detectou diferença significativa $(p \leq 0,05)$ da média de gols da zona dois (perto da meta), quando comparado com as demais (três, cinco, seis e oito). Então, o treino da visão periférica não permitiu um diferencial significativo para o GE fazer mais gols perto da meta, durante cada turno, pois aconteceram resultados similares com o GC. O GRÁFICO 1 ilustra a média de gols por zona do GE e do GC.

A TABELA 2 mostra a estatística descritiva da zona dos gols de todo o campeonato do GE e do GC. 
TABELA 1

ZONA DOS GOLS CONFORME O TURNO.

\begin{tabular}{lcccccc}
\hline Amostra & Turno & Zona 2 & Zona 3 & Zona 5 & Zona 6 & Zona 8 \\
\hline \multirow{2}{*}{ GE } & $1^{\circ}$ & $3 \pm 2,94$ & - & $1,50 \pm 1$ & - & - \\
& $2^{\circ}$ & $4,50 \pm 1,29$ & $0,25 \pm 0,5$ & $2 \pm 0,81$ & $0,25 \pm 0,5$ & - \\
& $3^{\circ}$ & $1,50 \pm 1,73$ & - & $3,50 \pm 1,29$ & - & $0,50 \pm 0,57$ \\
GC & $1^{\circ}$ & $2,75 \pm 2,21$ & - & $1,25 \pm 0,95$ & - & $0,25 \pm 0,5$ \\
& $2^{\circ}$ & $2,75 \pm 1,7$ & $0,25 \pm 0,5$ & $0,50 \pm 0,57$ & - & - \\
& $3^{\circ}$ & $3,50 \pm 2,38$ & - & $2,50 \pm 1,91$ & - & $1,50 \pm 1,91$ \\
\hline
\end{tabular}

\section{GRÁFICO 1 \\ MÉDIA DAS ZONAS DE GOLS EM CADA TURNO DO GE E DO GC.}

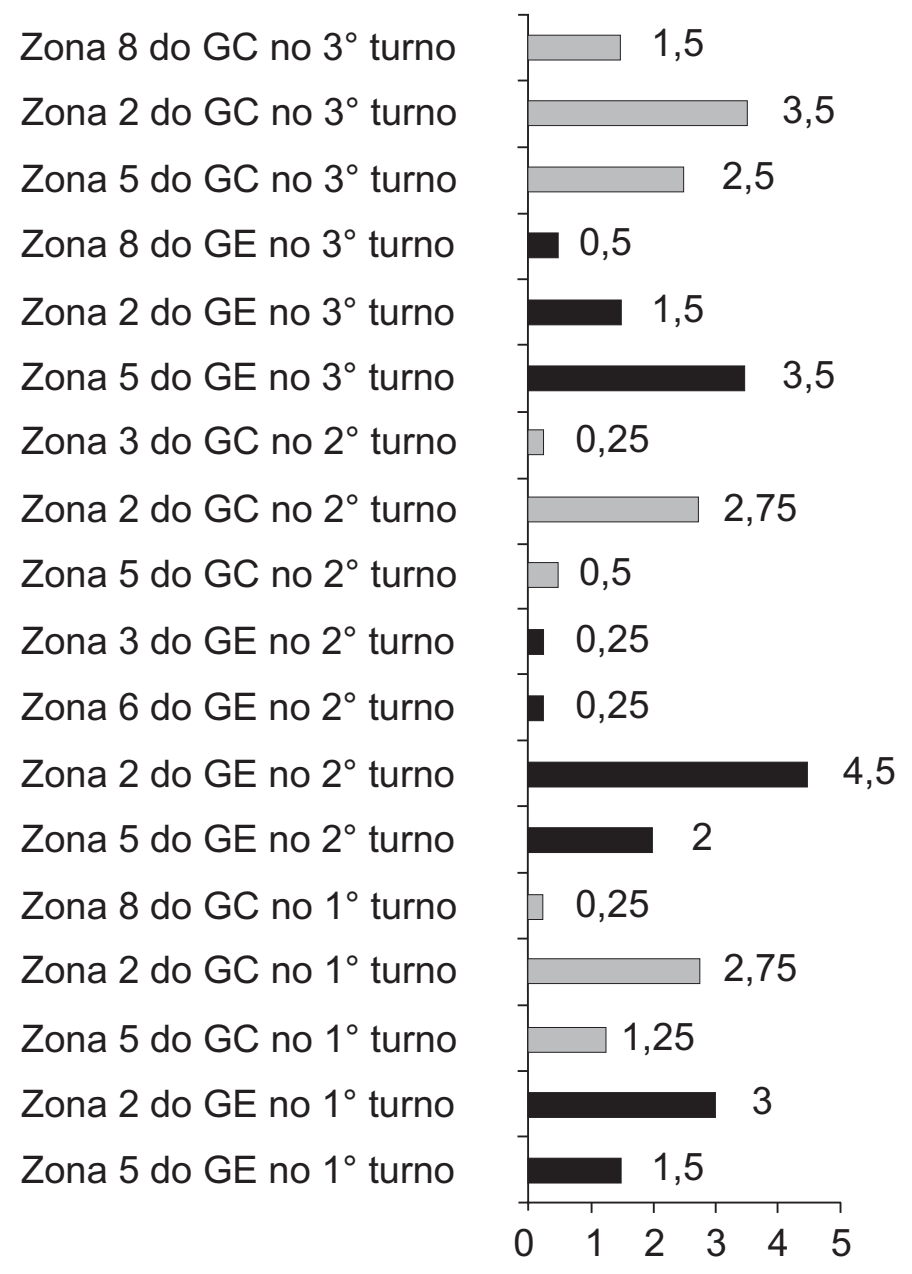

A TABELA 3 apresenta os resultados do teste " $\mathrm{t}$ " independente das comparações dos gols por zona de todo o campeonato entre o GE e o GC.
TABELA 2

ZONA DOS GOLS DE TODO O

CAMPEONATO.

\begin{tabular}{lccccc}
\hline Amostra & $\begin{array}{c}\text { Zona } \\
\mathbf{2}\end{array}$ & $\begin{array}{c}\text { Zona } \\
\mathbf{3}\end{array}$ & $\begin{array}{c}\text { Zona } \\
\mathbf{5}\end{array}$ & $\begin{array}{c}\text { Zona } \\
\mathbf{6}\end{array}$ & $\begin{array}{c}\text { Zona } \\
\mathbf{8}\end{array}$ \\
\hline GE & $9 \pm 2,94$ & $0,25 \pm 0,5$ & $7 \pm 1,41$ & $0,25 \pm 0,5$ & $0,50 \pm 0,57$ \\
GC & $9 \pm 3,36$ & $0,25 \pm 0,5$ & $4,25 \pm 0,95$ & & $1,75 \pm 1,7$ \\
& & & & & \\
\hline
\end{tabular}

As comparações entre o GE, versus o GC, no teste " $\mathrm{t}$ " independente, mostrou que a zona dois de gols, em todo o campeonato, foi a com mais tentos e, depois, a zona cinco (ambas próximas da meta). Mas o GE conseguiu mais tentos na zona cinco do que o GC, sendo significativo $(\mathrm{p} \leq 0,05)$. O GRÁFICO 2 apresenta a média de gols por zona de todo o campeonato do GE e do GC.

\section{DISCUSSÃO}

O GE e o GC fizeram mais gols na zona dois, em todo o campeonato. Estes resultados estiveram de acordo com Vilhena Silva, Moreira, Costa e Greco ${ }^{25}$. Na zona dois, ocorrem mais gols pois é perto e de frente para a meta. Amaral e Garganta ${ }^{26}$ evidenciaram, como as zonas mais propensas de gols, a cinco e a dois, sendo contrário ao do estudo de Vilhena Silva et al. ${ }^{25}$. Contudo, algo chamou atenção nos resultados da investigação. Quando o GE fez mais gols na zona dois (segundo turno, com 4,50 $\pm 1,29$ gols), a amostra havia praticado 15 sessões do treino da visão periférica. $O$ mesmo aconteceu com o GC (terceiro 
TABELA 3

RESULTADOS DO TESTE “T” INDEPENDENTE.

\begin{tabular}{|c|c|c|}
\hline Variável & Graus de liberdade & “t” \\
\hline Zona 5 do GE x Zona 5 do GC & 6 & $3,22^{*}$ \\
\hline Zona 5 do GE x Zona 2 do GC & 6 & $-1,09$ \\
\hline Zona 5 do GE x Zona 8 do GC & 6 & $4,73^{\star}$ \\
\hline Zona 5 do GE x Zona 3 do GC & 6 & $9^{*}$ \\
\hline Zona 2 do GE x Zona 5 do GC & 6 & $3,06^{*}$ \\
\hline Zona 2 do GE x Zona 2 do GC & 6 & 0 \\
\hline Zona 2 do GE x Zona 8 do GC & 6 & $4,26^{*}$ \\
\hline Zona 2 do GE x Zona 3 do GC & 6 & $5,86^{*}$ \\
\hline Zona 8 do GE x Zona 5 do GC & 6 & $-6,70^{*}$ \\
\hline Zona 8 do GE x Zona 2 do GC & 6 & $-4,97^{\star}$ \\
\hline Zona 8 do GE x Zona 8 do GC & 6 & $-1,38^{*}$ \\
\hline Zona 8 do GE x Zona 3 do GC & 6 & 0,65 \\
\hline Zona 3 do GE x Zona 5 do GC & 6 & $-7,40^{*}$ \\
\hline Zona 3 do GE x Zona 2 do GC & 6 & $-5,14^{*}$ \\
\hline Zona 3 do GE x Zona 8 do GC & 6 & 1,68 \\
\hline Zona 3 do GE x Zona 3 do GC & 6 & 0 \\
\hline Zona 6 do GE x Zona 5 do GC & 6 & $-7,40^{\star}$ \\
\hline Zona 6 do GE x Zona 2 do GC & 6 & $-5,14^{*}$ \\
\hline Zona 6 do GE x Zona 2 do GC & 6 & 1,68 \\
\hline Zona 6 do GE x Zona 3 do GC & 6 & 0 \\
\hline
\end{tabular}

$\mathrm{p} \leq 0,05^{\star}$

turno, com 3,50 $\pm 2,38$ gols), pois esse grupo realizou mais gols, na zona dois, quando realizou o treino da visão periférica. Esses achados estiveram conforme o esperado por Williams, Weigelt, Harris e Scott ${ }^{27}$, que afimam que, quando o atleta do futsal utiliza mais a visão periférica na partida, a equipe consegue mais sucesso competitivo. Fato observado na pesquisa, já que, no segundo turno, o GE foi campeão e, no terceiro turno, o GC foi o primeiro colocado. Ford, Hodges, Huys e Williams ${ }^{28}$, ainda, acrescentaram que o bom uso da visão resulta em chutes mais precisos para a meta. Reina, Moreno e Sanz ${ }^{29}$ lembraram que, em um estudo sobre visão no esporte, a pesquisa necessita de instrumentos de alta tecnologia para identificar, com precisão, para onde os jogadores estão olhando. Portanto, parece que o treino da visão periférica acarretou um incremento na quantidade de gols, na zona dois, no segundo turno do GE, e, no terceiro turno, do GC.

A zona cinco foi a segunda em maior número de gols de todo o campeonato do GE $(7 \pm 1,41)$ e do GC $(4,25 \pm 0,95)$. Isto aconteceu porque é uma zona que vai do meio-campo ofensivo ao ataque, sendo próxima à meta,

\section{GRÁFICO 2 \\ MÉDIA DA ZONA DE GOLS DE TODO O \\ CAMPEONATO DO GE E DO GC.}




propiciando muitas chances de gol ${ }^{30}$. Mas, para Vilhena Silva, Costa, Souza e Greco ${ }^{31}$, conforme a marcação realizada pelo oponente, os gols acontecem em uma zona da quadra. Consultando Suzuki e Nishijima ${ }^{32}$, talvez o alto índice de gols na zona cinco esteja relacionado com o sistema defensivo. Porém, Gréhaigne, Godbout e Bouthier $^{33}$ afirmaram que a visão periférica é fundamental no ataque, mas o técnico precisa identificar, também, como essa visão espacial é praticada durante a tomada de decisão nas jogadas. O presente estudo não contemplou este ponto, o que compromete o entendimento do motivo da grande quantidade de gols na zona cinco. Apesar das limitações, pode-se supor que o motivo do GE e do GC terem obtido resultados parecidos na zona de gols seja, talvez, a hemisfericidade. O GE e o GC tinham muitos atletas com hemisfério de processamento mental esquerdo, bom para tarefas analíticas. Entretanto, apesar dos resultados parecidos do GE e do GC, o teste " $\mathrm{t}$ " independente identificou, na zona cinco, diferença significativa $(p \leq 0,05)$ no número de gols, em todo o campeonato, com valores superiores para o GE, que fez mais o treino da visão periférica (25 sessões). Todavia, a causa do número de gols por zona quase iguais, do GE e do GC, não pode ser explicada.
Panchuk e Vickers ${ }^{4}$, em seus estudos, utilizaram uma mini-câmera, fixada próxima dos olhos do goleiro de hóquei, visando identificar a qualidade visual para efetuar as defesas. No presente trabalho, entretanto, somente podem ser levantadas hipóteses referente à zona de gols, à contribuição do treino da visão periférica no ataque, havendo carência de dados que possam explicar os valores parecidos das zonas de gols do GE e do GC.

\section{CONCLUSÕES}

O GE e o GC apresentaram resultados similares na zona de gols, não tendo, a presente pesquisa, encontrado explicação sobre esses achados. Talvez, a causa possa ser a não mensuração da qualidade da defesa e do goleiro, não identificando a qualidade da tomada de decisão dos jogadores e, o mais importante, não dispondo de equipamentos mais sofisticados, como uma mini-câmera nos olhos dos atletas, com o intuito de identificar para onde os pesquisados estavam observando durante o ataque. Esta pesquisa, entretanto, buscou mostrar como realizar o treino da visão periférica, educando o esportista do futsal a jogar de cabeça erguida na partida, proporcionando ênfase na visão espacial.

As limitações deste estudo servem para que os próximos sejam aperfeiçoados, a fim de identificar o efeito do treino da visão periférica na zona de gols do futsal.

\section{REFERÊNCIAS BIBLIOGRÁFICAS}

1. Horn R, William SM, Ensum J. Attacking in central areas: a preliminary analysis of attacking play in the 2001/2002 Premiership season. Insight 2002;5:28-31.

2. McPherson SL, Vickers JN. Cognitive control in motor expertise. Int J Sport Exerc Psychol 2004;2:274-300.

3. Ford P, Hodges NJ, Williams M. Examining action effects in the execution of a skilled soccer kick by using erroneous feedback. J Mot Behav 2007;39:481-90.

4. Panchuk D, Vickers JN. Gaze behaviors of goaltenders under spatial-temporal constraints. Hum Mov Sci 2006;25:733-52.

5. Williams M. Perceptual and cognitive expertise in sport. Psychol 2002;15:416-7.

6. Lemmink KAPM, Dijkstra B, Visscher C. Effects of limited peripheral vision on shuttle sprint performance of soccer players. Percept Mot Skills 2005;100:167-75.

7. McGarry T, Franks IM. On winning the penalty shoot-out in soccer. J Sports Sci 2000;18:401-9.

8. Van Der Kamp J. A field simulation study of the effectiveness of penalty kick strategies in soccer: late alterations of kick direction increase errors and reduce accuracy. J Sports Sci 2006;24:467-77.

9. Navarro AC, Almeida R. Futsal. São Paulo: Phorte; 2008.

10. Marques Junior NK. O efeito do treino da visão periférica no ataque de iniciados do futsal: um estudo na competição [dissertação]. Rio de Janeiro: UCB; 2008. p. 157. 
Revista de Educação Física 2008 Dez 143:18-27. Rio de Janeiro (RJ) - Brasil.

11. Williams M, Hodges NJ. Practice, instruction and skill acquisition in soccer: challenging tradition. J Sports Sci 2005;23:637-650.

12. Arins FB, Rosendo da Silva RC. Intensidade de trabalho durante os treinamentos coletivos de futsal profissional: um estudo de caso. Rev Bras Cineantropom Desempenho Hum 2007;9:291-6.

13. Queiroga MR, Ferreira SA, Pereira G, Kokubun E. Somatotipo como indicador de desempenho em atletas de futsal feminino. Rev Bras Cineantropom Desempenho Hum 2008;10:56-61.

14. Matsudo VKR. Testes em ciências do esporte. 6ª ed. São Caetano do Sul: CELAFISCS; 1998.

15. Oliveira FA, Beltrão FB, Da Silva VF. Metacognição e hemisfericidade em jovens atletas. Rev Paul Educ Fís 2003;17:5-15.

16. Marques Junior NK. Periodização tática: o treinamento de iniciadas do futebol de salão feminino de 2006. Mov Percep 2007;8:7-41.

17. Tani G. Comportamento motor: aprendizagem e desenvolvimento. Rio de Janeiro: Guanabara Koogan;2005.

18. Harman EA, Rosenstein MT, Frykman PN, Rosenstein RM. The effects of arms and countermovement on vertical jumping. Med Sci Sports Exerc 1990;22:825-33.

19. Rocha CM, Ugrinowitsch C, Barbanti VJ. A influência do contramovimento e da utilização dos braços na performance do salto vertical - um estudo no basquetebol de alto nível. Rev APEF 1999;14:5-12.

20. Baker J, Horton S, Robertson-Wilson J, Wall M. Nurturing sport expertise: factors influencing the development of elite athletes. J Sports Sci Med 2003;2:1-9.

21. Correia da Silva T. Programação de revelação de aptidões e capacidades desportivas de atletas portadores de altas habilidades no futebol brasileiro [dissertação]. Rio de Janeiro: UCB; 2003. p. 220.

22. Guadagnoli MA, Lee TD. Challenge point: a framework for conceptualizing the effects of various practice conditions in motor learning. J Mot Behav 2004;36:212-24.

23. Jackson RC, Baker JS. Routines, rituals, and rugby: case study of a world class goal kicker. Sport Psychol 2001;15:48-65.

24. Oslin JL, Mitchell SA, Griffin LL. The game performance assessment instrument (GPAI): development and preliminary validation. J Teach Physic Educ 1998;17:231-43.

25. Vilhena Silva M, Moreira JPA, Costa F, Greco P. Comparision between the offensive actions of the final stage of the mineiro championship of indoor soccer in the pre mirim and mirim categories. Fiep 2005;75:284-7.

26. Amaral R, Garganta J. A modelação do jogo em futsal. Análise seqüencial do $1 \times 1$ no processo ofensivo. Rev Port Ciên Desp 2005;3:298-310.

27. Williams M, Weigelt C, Harris M, Scott MA. Age-related differences in vision and proprioception in a lower limb interceptive task: the effects of skill level and practice. Res Q Exerc Sport 2002;73:386-95.

28. Ford P, Hodges NJ, Huys R, Williams M. The role of external action-effects in the execution of a soccer kick: a comparison across skill level. Mot Contr 2006;10:386-404.

29. Reina R, Moreno FJ, Sanz D. Visual behavior and motor responses of novice and experienced wheelchair tennis player relative to the service return. Adpt Physic Activit Q 2007;24:254-71.

30. Taylor S, Williams M. A quantitative analysis of Brazil`s performance. Insight 2002;5:29-32.

31. Vilhena Silva M, Costa F, Souza P, Greco P. Ações ofensivas no futsal: uma comparação entre as situações de jogo organizado de contra-ataque e de bola parada. Rev Port Ciên Desp 2004;4:199. 
32. Suzuki K, Nishijima T. Sensitivity of the soccer defending skill scale: a comparison between teams. Eur J Sports Sci 2007;7:35-45.

33. Gréhaigne J-F, Godbout P, Bouthier D. The teaching and learning of decision making in team sports. Quest 2001;53:59-76.

\section{Endereço para correspondência:}

Nelson Kautzner Marques Junior Rua 5, Lote 12, Quadra D - Loteamento Jardim Fluminense Itaipu - Niterói / RJ - Brasil CEP: 24344-080 e-mail: nk-junior@uol.com.br

\section{ANUNCIE NA}

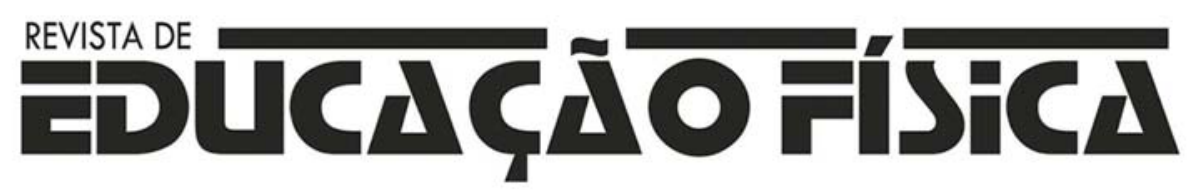

Versão impressa distribuída para 5.000 assinantes (Bibliotecas, Entidades de Ensino Superior em Educação Física, Nutrição, Medicina Esportiva...)

Versão on-line distribuída para 23.000 assinantes (Academias de Ginástica, Estudantes, Professores, Confederações, Equipes Desportivas, Atletas...)

\section{CONTATOS: (21) 2533-4606}

